\title{
Does Patient-Centered Care Mean that Informed Consent is Necessary for Clinical Performance Measures?
}

\author{
R. Scott Braithwaite, MD, MS, FACP' and Arthur Caplan, $P h D^{2}$ \\ 'The Division of Comparative Effectiveness and Decision Science, Department of Population Health, New York University School of Medicine, \\ New York, NY, USA; 'Division of Bioethics, Department of Population Health, New York University School of Medicine, New York, NY, USA.
}

\author{
KEY WORDS: patient centered care; performance measurement; \\ informed consent; decision making. \\ J Gen Intern Med 29(4):558-9 \\ DOI: $10.1007 / \mathrm{s} 11606-013-2645-4$ \\ (C) The Author(s) 2013. This article is published with open access at \\ Springerlink.com
}

T here is great enthusiasm for new models for health systems that may promote patient-centered decision making, such as patient-centered medical homes. ${ }^{1}$ The purpose of patient-centered decision making is to allow each patient to make an informed decision, taking into account their preferences while knowing potential harms and benefits; it is an important facet of patient-centered care. ${ }^{2}$ However, at the same time as patient-centered care is being pursued, clinical performance measures are proliferating (for example, requiring diabetics to have hemoglobin $\mathrm{A} 1 \mathrm{Cs} \leq 7) .{ }^{3}$ Whereas patient-centered care seeks to tailor decisions based on the harms and benefits for individual patients, and how individual patients value those harms and benefits, performance measures seek to standardize care, therefore pushing in the opposite direction. Clinical performance measures serve the vital function of extending the reach of evidence-based interventions that provide clinical benefit. Given the vast reservoir of preventable morbidity and mortality in the United States, clinical performance measures are also crucial for healthcare systems, even though they may occasionally conflict with patient-centered care.

How can patient-centered care coexist with clinical performance measures? One approach would be to identify patients with preferences that conflict with a particular clinical performance measure. Such patients would have the option of declining to meet the performance measure, which would remove them from the "denominator" when achieving that performance measure is calculated. It may be noted that if clinical performance measures were constructed to exclude patients who refuse to participate or who are otherwise 'nonstandard' (e.g., unusual preferences), this could make them unsuitable candidates for any formal consent process. However, clinical performance measures are generally not constructed or implemented with explicit consideration of nonstandard patients.

Consider a typical patient for whom the non-health benefit from declining a performance measure may exceed the health

Published online October 22, 2013 benefit from assenting to that performance measure: a diabetic with a short life expectancy due to multiple chronic diseases, who is well-informed about potential diabetes complications and the importance of complying with the diabetes performance measures (e.g. obtaining a hemoglobin A1C below 7), yet values these health benefits less than the non-health benefits of avoiding the logistical hassles of additional medications and needle sticks. This patient should have the option of refusing to consent to the diabetes performance measure, and to have this refusal documented through an informed consent procedure. Then that patient would be removed from the denominator when that measure is calculated. Patient-centered decisions to ignore performance standards would then not "count against" the physician or the health system by lowering their grades on the particular performance measure. Additionally, requiring a formal "optout" process would guard against practitioners "gaming" the system by simply removing all nonadherent patients from their assessments.

Of course, competent patients always have the option of declining care. But given that some clinical environments pursue clinical performance measure targets with sufficient zeal so as to nearly constitute a coercive environment, practitioners facing such pressures are less likely to engage in a shared decision involving communication of harms and benefits.

\section{INDIVIDUAL RIGHTS VERSUS SOCIETAL GOOD}

Some ethicists may wonder if the question of opting out of performance measures would be more appropriately framed as a tension between individual rights versus social good. For example, a diabetic patient refusing to meet treatment guidelines because of personal choice may impose an inappropriate burden on society by encroaching on the rights of a population not to pay for poor choices made by others. However, it is important to keep in mind that this argument seldom applies in clinical care. The overwhelming majority of clinical care, performance measures included (for example, hemoglobin A1C standards for diabetics), is cost-generating rather than cost-saving. In the minority of situations in which opting out of performance measures may impose a financial burden on others, it is more consistent with patient autonomy 
to impose a tax (or, equivalently, increased cost-sharing) to offset these increased costs, rather than to violate autonomy by mandating compliance.

\section{LIMITATIONS OF INFORMED CONSENT}

Informed consent is sometimes viewed negatively by clinicians, because its legal origins have led to language that is often incomprehensible, particularly to patients with low numeracy and literacy, and sometimes even to clinicians themselves. Informed consent documents often read like a laundry list, and fail to explicate the likelihood and severity of different adverse events. Additionally, informed consent can be susceptible to coercion and manipulation. However, informed consent can be more effectively implemented when it also encompasses decision aids ${ }^{4}$ and other approaches that provide comprehensible information about harms and benefits, using risk communication methods that have been shown to increase comprehension and decision satisfaction.

Not all clinical performance measures require informed consent. Generally, informed consent would be relevant to only those measures that are "preference sensitive," 5 meaning it is plausible that a reasonable person might value the non-health benefits of avoiding an intervention more than the health benefits of receiving that intervention. For example, the performance guideline requiring a short time until administration of antibiotics for a patient admitted for pneumonia does not correspond to a preference-sensitive decision, and therefore would be an unsuitable use of an informed consent procedure.

Additionally, using informed consent to facilitate patientcentered care requires an evolution in how informed consent is contextualized, from applying exclusively to acts of commission to applying to acts of omission. Organizations and practitioners are often reluctant to change longestablished practices even when better, more effective and cheaper alternatives exist. Patients have a right to know when this is so, and practice guidelines ought to be attentive to such circumstances.

\section{OTHER SITUATIONS IN WHICH INFORMED CONSENT WOULD NOT APPLY}

If harm is likely to exceed benefit (as may occur, for example, if patients with high comorbidity burdens are offered prophylactic surgery to repair aortic aneurysms, which carries greater risks than benefits, yet is a common phenomenon), it can be argued that it is unethical to offer the service to the patient at all. Thus, informed consent is a moot issue. It is also important to note that if harm to the patient from a performance measure is extremely small compared to benefit to society (e.g. influenza vaccinations), it may be argued that it is unethical for a patient to decline, and therefore informed consent would be unnecessary.

\section{CONCLUSION}

In summary, patient-centered care proposes to allow a patient to make an informed decision, taking into account his/her preferences and knowing the harms and benefits of a particular activity. It can be argued that informed consent should be employed when pursuit of clinical performance is potentially in conflict with patient-centered care. The type of informed consent that would be most suitable for patient-centered care would be the clinically oriented (e.g. decision aids) rather than the legally oriented dimension of the concept.

\section{Acknowledgements:}

Funding: None.

Conflicts of Interest: The authors declare that they do not have a conflict of interest.

Corresponding Author: R. Scott Braithwaite, MD, MS, FACP; Division of Comparative Effectiveness and Decision Science, Department of Population Health, New York University School of Medicine, 550 First Avenue, VZ30 6th floor, 615, New York, NY 10016, USA (e-mail: Scott.braithwaite@nyumc.org).

Open Access This article is distributed under the terms of the Creative Commons Attribution License which permits any use, distribution, and reproduction in any medium, provided the original author(s) and the source are credited.

\section{REFERENCES}

1. Stange KC, Nutting PA, Miller WL, et al. Defining and measuring the patient-centered medical home. J Gen Intern Med. 2010;25(6):601-12.

2. Davis K, Schoenbaum SC, Audet AM. A 2020 vision of patient-centered primary care. J Gen Intern Med. 2005;20(10):953-7.

3. Braithwaite RS. Can life expectancy and GALYs be improved by a framework for deciding whether to apply clinical guidelines to patients with severe comorbid disease? Med Decis Making. 2011;31(4):582-95.

4. O'Connor AM, Bennett C, Stacey D, et al. Do patient decision aids meet effectiveness criteria of the international patient decision aid standards collaboration? A systematic review and meta-analysis. Med Decis Making. 2007;27(5):554-74.

5. Keirns CC, Goold SD. Patient-centered care and preference-sensitive decision making. JAMA. 2009;302(16):1805-6. 